\title{
IMPACTOS AMBIENTAIS DECORRENTES DA INSTALAÇÃO DO RODOANEL NA ZONA PERIURBANA DE TERESINA- PI
}

\author{
José Maria Marques de Melo Filho' \\ Giovana Mira de Espindola ${ }^{2}$ \\ Antonio Cardoso Façanha ${ }^{3}$
}

\begin{abstract}
RESUMO
A implantação de obras viárias, considerando-se sua extensão e todos os processos envolvidos em sua execução, desde a instalação, elaboração e definição de traçado, deve, necessariamente, estar alinhada com o processo de licenciamento ambiental e de análise das alterações no meio ambiente, bem como contemplar as alterações sociais provocadas por uma intervenção desta magnitude. Assim, nesta pesquisa buscou-se discutir como o processo de implantação do rodoanel em Teresina provocou alterações no meio ambiente, e como afetou os assentamentos rurais localizados no entorno da obra viária. Para alcançar o objetivo proposto, utilizou-se como alicerce uma perspectiva dialética, tendo em vista o exame de fenômenos, não apenas por meio de suas relações mútuas, mas também de suas transformações e desenvolvimento. Neste sentido, a fundamentação das discussões realizadas teve como aporte teórico os dados coletados em pesquisa bibliográfica e documental, e ainda com base em visitas de campo realizadas aos assentamentos rurais. Já a representação espacial dos fenômenos estudados foi realizada por meio da produção dos mapas temáticos e registro fotográfico. Tomando como parâmetro a realização do empreendimento rodoviário, percebeu-se a falta de cuidado no cumprimento das regulamentações legais e deficiências nos estudos de avaliação efetivados, conduzindo dessa maneira, para situações de conflitos e desequilíbrio ambiental.
\end{abstract}

Palavras-chave: Impactos ambientais. Expansão urbana. Rodoanel.

\footnotetext{
${ }^{1}$ Mestre em Desenvolvimento e Meio Ambiente (PRODEMA/UFPI) e Doutorando no Programa de Pósgraduação em Geografia da Universidade Federal do Paraná - UFPR. E -mail: josemarquesprofgeo@gmail.com.

${ }^{2}$ Profa. Doutora do curso de mestrado em Desenvolvimento e Meio Ambiente (PRODEMA), e do curso de mestrado em Geografia (PPGGEO), ambos da Universidade Federal do Piauí - UFPI. Email:giovanamira@gmail.com

${ }^{3}$ Prof. Doutor do curso de Mestrado em Geografia (PPGGEO) e do Mestrado em Desenvolvimento e Meio Ambiente (PRODEMA) da Universidade Federal do Piauí - UFPI. E-mail:facanha@ufpi.edu.br

R. gest. sust. ambient., Florianópolis, v. 10, n. 2, p. 45-64, jun. 2021.
} 


\title{
ENVIRONMENTAL IMPACTS ARISING FROM THE INSTALLATION OF THE RING ROAD IN THE PERIURBAN AREA OF TERESINA- PI
}

\begin{abstract}
The implementation of roadworks, considering its extension and all the processes involved in its execution (including the aspects associated with installation, elaboration and layout definition) must be aligned with the process of environmental licensing and analysis of the changes in the environment, as well as to contemplate the social changes caused by such intervention. Thus, the present study aimed to discuss how the implementation process of the ring road in Teresina has caused changes in the environment, and how it has affected the rural settlements located around the roadwork. To achieve the objective proposed, a dialectical perspective was used as foundation, which was based not only on the mutual relations of different phenomena examined, but also through their transformations and development. Therefore, the basis for the discussions had as theoretical support the data collected in bibliographic and documentary research, as well as field visits made to rural settlements. The spatial representation of the studied phenomena was performed through the production of thematic maps and photographic records. Having the roadwork as a parameter, it was noticed the lack of attention regarding the compliance of legal regulations and deficiencies in the evaluation studies that were carried out, thus leading to situations of conflict and environmental imbalance.
\end{abstract}

Keywords: Environmental Impacts. Urban Expansion. Ring Road.

\section{AS IMPLICAÇÕES DO PROCESSO DE EXPANSÃO URBANA EM TERESINA}

A cidade de Teresina encontra-se localizada no Centro Norte do Piauí, sendo referência e destaque como "pólo regional de saúde e educação" (TERCEIRO; CARNEIRO e ESPINDOLA, 2018). A capital piauiense foi na sua origem planejada para alavancar o desenvolvimento do Estado, em substituição à antiga sede, Oeiras (SILVA; FAÇANHA, 2016). A partir de então, transformou-se no principal eixo de atração e oferta de serviços e comércio, concentrando um grande contingente populacional, servindo também de interligação entre a capital com outros municípios do estado, bem como outras capitais do país (ESPINDOLA; CARNEIRO e FAÇANHA, 2017)

A expansão urbana de Teresina elevou-se ao longo dos anos, sobretudo, pelos investimentos do Governo Federal, registrando nos anos 2000, uma taxa de crescimento urbano de $94,2 \%$, mas quando observamos os dados sobre a dimensão do município em relação a sua área urbanizada, constatamos que somente $17 \%$, é

R. gest. sust. ambient., Florianópolis, v. 10, n. 2, p. 45-64, jun. 2021. 
urbano, e 83\%, é rural (IBGE, 2010). Conclui-se, portanto, que embora o espaço urbano do município compreenda uma menor parcela em dimensão territorial, a abrangência dos processos que incidem sobre o urbano, provocam transformações socioespaciais na zona rural do município.

A própria incorporação de novas áreas ao perímetro urbano de Teresina, intensifica práticas especulativas e favorece, por exemplo, a atuação dos agentes imobiliários na busca de terrenos a baixo custo para a construção de condomínios de luxo destinados à população de alta renda que buscam as amenidades das áreas afastadas do centro urbano. A expansão urbana provoca, então, a abertura e pavimentação de vias e a instalação de outros equipamentos urbanos, alterando a paisagem local (LIMA; LOPES e FAÇANHA, 2017).

Os povoados localizados na zona rural possuem relativa proximidade com a capital, além disso, as vias de acesso facilitam o deslocamento da população residente nesses espaços, seja utilizando o transporte coletivo ou individual, acarretando uma gradativa transformação dos espaços rurais, pois tais aspectos favorecem a penetração e reprodução do capital e, consequentemente, mudanças em seu modo de vida (CASTRO NETO; BATISTA e ABREU, 2011).

O espaço rural do município constitui-se em um espaço híbrido, ou seja, um espaço rural com características tipicamente urbanas. Essa incorporação do modo de vida urbano ao espaço rural teve como um de seus fatores condicionantes o acelerado processo de expansão urbana, implicando na reprodução do modo de vida capitalista.

De acordo com Silva e Façanha (2016), o crescimento urbano da capital, implicou na fragmentação do espaço, estimulando o aparecimento de novas centralidades e, consequentemente, estes centros necessitam atender novas demandas de transportes, trânsito e serviços aumentando os gastos com infraestrutura urbana. Em razão disso, visando o melhoramento da infraestrutura urbana do município, investimentos foram realizados na ampliação de sua malha viária. A implantação do rodoanel em Teresina representa uma das obras destinadas a promover a melhoria do tráfego no município.

O empreendimento rodoviário tem por finalidade reduzir a circulação de veículos transportando cargas pesadas na área central da capital, diminuindo os congestionamentos. Essa intervenção urbana, entretanto, provocou intensas modificações na dinâmica socioespacial da zona rural do município, pois para sua

R. gest. sust. ambient., Florianópolis, v. 10, n. 2, p. 45-64, jun. 2021. 
construção houve o desmatamento de uma extensa área de cobertura vegetal, além da invasão de terras de assentamentos da reforma agrária e comprometimento de mananciais e encostas.

Assim, consoante com o exposto, a pesquisa teve como objetivo analisar como o processo de implantação do rodoanel em Teresina provocou alterações significativas no meio ambiente, além de afetar os assentamentos rurais encontrados no entorno da obra viária, dando ênfase às discussões sobre o processo, as ações na gestão da obra, e as alterações ambientais na área em análise, como por exemplo, a perda de área produtiva, assoreamento dos olhos d’água, e perda da vegetação.

\section{METODOLOGIA}

O rodoanel em análise visa desviar o tráfego de veículos pesados (carretas, caminhões, etc.), reduzindo o congestionamento no interior do perímetro urbano da cidade de Teresina. A pesquisa tem como enfoque a implantação da rodovia que apresenta uma extensão de 28,26 km e está localizado no município de Teresina, como apresentado na Figura 01. O rodoanel tem seu ponto inicial localizado no km 12, da rodovia federal BR - 316 (Teresina/Demerval Lobão) e ponto final localizado no km 332 da rodovia federal BR - 343 (Teresina/Altos).

$\mathrm{Na}$ área de estudo existem os seguintes projetos de assentamentos rurais implantados com recursos do governo federal, sob a responsabilidade do Instituto Nacional de Colonização e Reforma Agrária (INCRA), que são: Assentamento Nossa Vitória (com 64 famílias residentes), Assentamento Santana/Nossa Esperança (com 150 famílias) e Assentamento Vale da Esperança (com 64 famílias), perfazendo um total geral de 278 famílias assentadas (Figura 01).

R. gest. sust. ambient., Florianópolis, v. 10, n. 2, p. 45-64, jun. 2021. 
Figura 01 - Mapa da área do rodoanel de Teresina - PI.

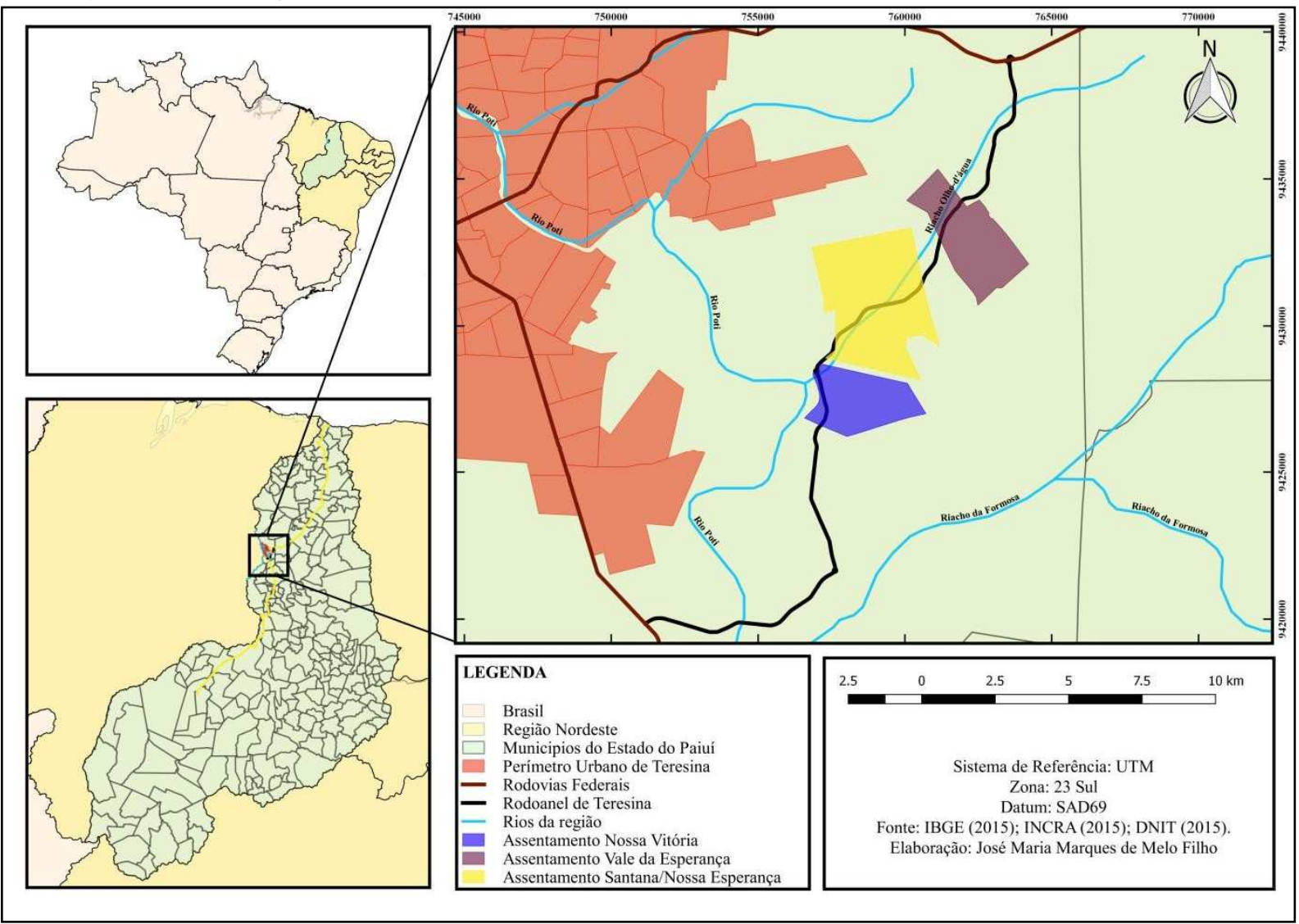

Fonte: Elaborado por MELO FILHO, 2019.

A metodologia de pesquisa englobou pesquisa de fontes, fundamentos e procedimentos envolvendo o tratamento e avaliação das informações. Como afirma Silva e Menezes (2005), somente se alcança o êxito esperado no trabalho de pesquisa quando os domínios sobre as técnicas auxiliam no conhecimento da apresentação do referencial teórico e por meio das interpretações dos dados obtidos confirmam ou negam as hipóteses, permitindo suscitar novas perspectivas de análise sobre o fenômeno examinado.

Após o levantamento bibliográfico da literatura básica referente aos conteúdos específicos da temática trabalhada, seguiu-se para a análise documental que englobou: a Política Nacional do Meio Ambiente (PNMA); Resoluções do Conselho Nacional do Meio Ambiente (CONAMA) e, ainda, os Programas de Controle Ambiental (PCA's) de pavimentação asfáltica e construção de ponte sobre o rio Poti, bem como o Relatório dos danos ambientais causados pelo rodoanel de Teresina nos projetos de assentamento Nossa Vitória, Vale da Esperança e Santana/Nossa Esperança feitos pelo INCRA.

R. gest. sust. ambient., Florianópolis, v. 10, n. 2, p. 45-64, jun. 2021. 
Os documentos oficiais analisados serviram para subsidiar a investigação realizada sobre as alterações trazidas pela construção do rodoanel. Na construção do levantamento de dados, foram realizadas também visitas aos assentamentos para a realização do trabalho de campo e do registro fotográfico.

\section{OS INSTRUMENTOS DE AVALIAÇÃO AMBIENTAL PARA OBRAS VIÁRIAS}

A revisão dos instrumentos de planejamento e gestão ambientais utilizados no processo decisório para determinar a elaboração de projetos que visam promover uma melhoria da infraestrutura urbana, sem, contudo, gerar maiores impactos ao meio ambiente, permite compreender as articulações, conflitos e deficiências entre 0 regulamentado institucionalmente e sua execução prática.

As regulamentações ambientais adotadas na implantação de grandes obras estruturais surgiram em consequência da maior preocupação do homem com os desequilíbrios provocados pela ação antrópica ao meio natural. Com a intensificação dessa preocupação atrelada com outros fatores, foi instituída, em 1981, a Lei no 6.938/81 que dispõe sobre a Política Nacional do Meio Ambiente - PNMA, consolidando instrumentos legais para a avaliação de impactos referente às atividades efetivas ou potencialmente poluidoras ao meio ambiente (BRASIL, 1981).

Nesta referida lei, em seu Art. 9o, Inciso IV, fica estabelecido que o licenciamento ambiental constitui um instrumento da PNMA, sendo que no Art. 10, $\S 1^{\circ}$, em seguida, é efetivado o cumprimento de licenciamento prévio para atividades causadoras de impacto a natureza e dá outras providências.

O licenciamento ambiental é um instrumento administrativo que visa garantir a redução dos danos provocados ao meio ambiente e por meio de sua análise buscar promover medidas mitigadoras para os mesmos. Dessa maneira, garantindo um melhor aproveitamento dos recursos naturais e equilíbrio do ecossistema (LEITE; SOBRAL e BARRETO, 2011).

Conforme Bandeira; Floriano (2004), os impactos gerados por obras de infraestrutura urbana, como por exemplo, obras viárias, iniciam desde seu planejamento, prosseguem na fase de instalação, e continuam até chegar à etapa final de operalização. Por isso que "para avaliar o desempenho ambiental das obras rodoviárias, atividades de supervisão ambiental devem ser realizadas sistemática e

R. gest. sust. ambient., Florianópolis, v. 10, n. 2, p. 45-64, jun. 2021. 
periodicamente durante todo o período de execução das obras" (COSTA; SÁNCHEZ, 2010, p. 248).

Dessa maneira, como disposto na PNMA, o órgão consultivo e deliberativo responsável por estabelecer normas e critérios para o licenciamento ambiental é de competência do Conselho Nacional do Meio Ambiente - CONAMA, com a devida supervisão do Instituto Brasileiro do Meio Ambiente e dos Recursos Naturais Renováveis (IBAMA) (BRASIL, 1981).

Sendo assim, o CONAMA editou algumas resoluções estabelecendo critérios, dando providências e diretrizes gerais sobre as normas para a realização do licenciamento (OLIVEIRA; MEDEIROS, 2007). Dentre as resoluções que deliberam sobre as atividades efetivas ou potencialmente poluidoras, como por exemplo, as obras de estruturação viária, destacam-se as seguintes: Resolução no 001, de 23 de janeiro de 1986, que dá as diretrizes gerais e normas de licenciamento para empreendimentos; Resolução no 006, de 16 de setembro de 1987, que edita regras gerais para licenciamentos ambientais de obras de grande porte; Resolução no 009 , de 03 de dezembro de 1987, que disciplina a realização de audiências públicas, para a exposição do RIMA; Resolução № 237, de 19 de dezembro de 1997, que revisa alguns procedimentos e critérios utilizados no licenciamento ambiental, postos na Resolução nº 001/86.

Com a criação da Resolução 01/86 do CONAMA, a Avaliação de Impactos Ambientais (AIA) apresentou novos instrumentos de intervenção, além de assegurar maior supervisão sobre os aspectos inerentes ao processo de implantação de atividades danosas ao ambiente (ARAÚJO, 2002). Desse modo, em seu Art. 2ํa Resolução descreve as atividades que dependem de elaboração de Estudo e Relatório de Impacto Ambiental (EIA/RIMA). Na mesma resolução referida, no Inciso $\mathrm{I}$, as estradas de rodagem com duas ou mais faixas de rolamento (como é o caso do rodoanel de Teresina) devem apresentar o referido estudo ambiental.

Com relação as atividades técnicas a serem desenvolvidas em um estudo de EIA/RIMA, determina a elaboração do diagnóstico ambiental; a análise dos impactos ambientais do projeto e de suas alternativas; a definição de medidas mitigadoras dos impactos negativos e, por fim, a elaboração de programa de acompanhamento e monitoramento dos impactos previstos (BRASIL, 1986).

R. gest. sust. ambient., Florianópolis, v. 10, n. 2, p. 45-64, jun. 2021. 
Por meio deste instrumento de avaliação de impacto, composto por um conjunto de procedimentos, pretende-se assegurar, desde seu começo até a sua fase final, exames sistemáticos sobre os impactos ambientais gerados, além de oferecer resultados que possam ser verificados e servir de parâmetros para uma melhor tomada de decisão, pois o estudo congrega aspectos técnicos, administrativos, sociais e ambientais (CRUZ; CRUZ e ROSSATO, 2014).

Entretanto, Araújo (2002) argumenta que as definições estabelecidas nesta resolução podem gerar dúvidas quanto à obrigatoriedade do EIA/RIMA, visto que alguns defendem outra interpretação do exposto na lei, no que se refere a lista que consta detalhada nos Incisos de I a XVIII, que poderia possui apenas caráter exemplificativo, cabendo ao órgão licenciador responsável verificar a necessidade ou não de determinado estudo e por meio de sua avaliação identificar a verdadeira significância ambiental do empreendimento proposto. Todavia, a utilização do EIA/RIMA configura-se como instrumento importante para garantir a defesa do meio ambiente (MUZZOLON JÚNIOR, 2014).

Neste caso, conforme a legislação vigente alguns empreendimentos em seu processo de licenciamento deve apresentar as licenças ambientais, garantindo o cumprimento do disposto na forma da lei. Cada uma das licenças concedidas possui uma determinada função e prazo de estabelecimento (MORAES, 2016). Com esses dispositivos de licitação e elaboração do EIA/RIMA torna-se possível, inclusive, caso seja identificado, a necessidade de mudanças no traçado de rodovias ou mesmo o impedimento da construção de determinado trechos, que possam causar impactos no meio ambiente, bem como atrelar novas tecnologias para beneficiar a redução de outros danos (MUZZOLON JÚNIOR, 2014).

Cabe ressaltar ainda, que, a avaliação dos impactos e a realização do EIA/RIMA deve contar com uma equipe interdisciplinar para que todas as esferas inerentes ao processo de licenciamento sejam contempladas, assim como a determinação de um método de avaliação capaz de atender as particularidades do empreendimento analisado (LEITE, SOBRAL e BARRETO, 2011).

Portanto, em relação aos aspectos jurídico-administrativos existentes e estabelecidos pela legislação brasileira para a gestão ambiental para obras de infraestrutura urbana, observa-se que caso as determinações elaboradas sejam seguidas, espera-se que as avaliações possam minimizar os danos causados com

R. gest. sust. ambient., Florianópolis, v. 10, n. 2, p. 45-64, jun. 2021. 
sua execução, ou seja, promover a implantação das obras sem que haja um grande comprometimento do meio ambiente.

\section{O PROJETO DO RODOANEL: CARACTERÍSTICAS GERAIS, HISTÓRICO DA OBRA E PRINCIPAIS ENTRAVES}

A obra viária em análise visa desviar o tráfego de veículos pesados da área central da capital de Teresina. O empreendimento citado apresenta as seguintes características técnicas: uma rodovia de classe II, com largura de pista de rolamento de 7,0 metros e largura de encostamento 2,5 metros para cada lado da via. A Secretaria de Estado dos Transportes (SETRANS) é a responsável pela realização do empreendimento, tendo como órgão ambiental licenciador a SEMAR, seguindo o previsto na Resolução 237/96 do CONAMA.

Conforme essa mesma Resolução, em seu Art. 2ํㅡ, Inciso I, a implantação de empreendimentos rodoviários deve realizar prévio estudo e relatório de impacto ao meio ambiente (EIA/RIMA) para obter as licenças necessárias a sua execução (BRASIL, 1996). Porém, para a obra em questão, foram elaborados dois Planos de Controle Ambiental (PCA). O primeiro PCA - para os serviços de implantação e pavimentação asfáltica, e o segundo PCA - referente às obras de implantação da ponte sobre o rio Poti, os relatórios ambientais foram realizados pela mesma empresa de consultoria ambiental.

Figura 02 - Processo de Implantação do Rodoanel

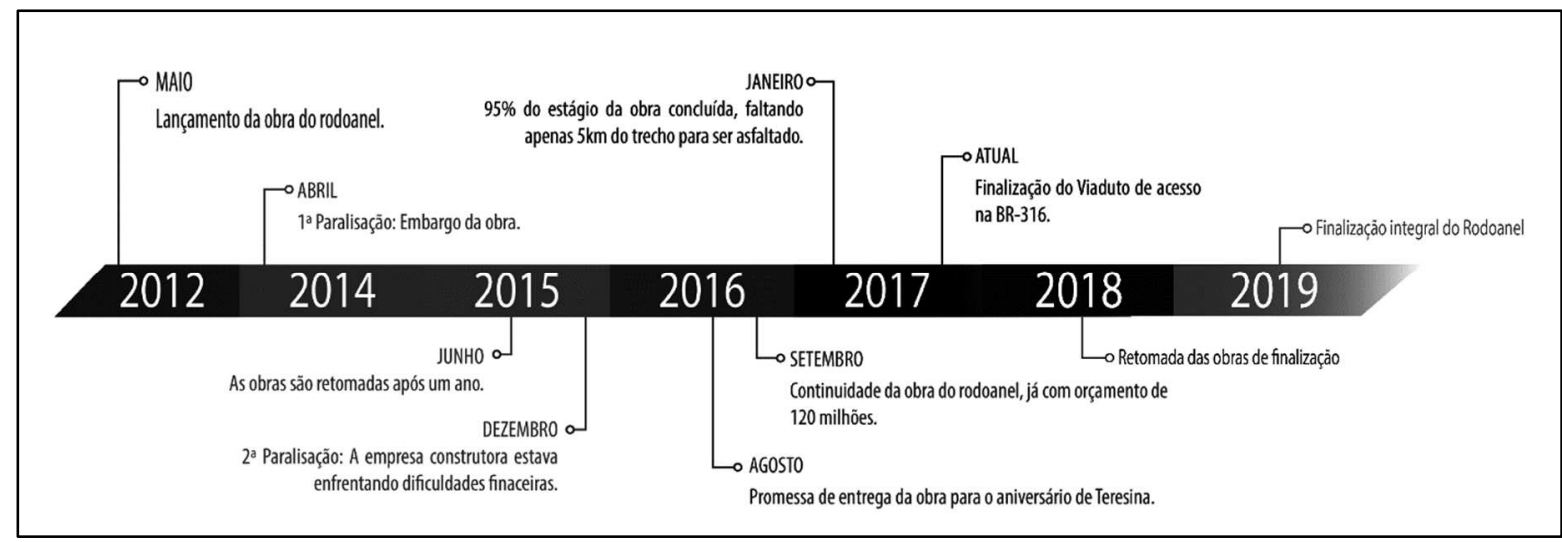

Fonte: Elaborado por MELO FILHO, 2019.

Contudo, o processo de instalação da obra rodoviária apresentou, durante o período de sua execução vários entraves, inclusive, um deles relacionado à falta de R. gest. sust. ambient., Florianópolis, v. 10, n. 2, p. 45-64, jun. 2021. 
elaboração do EIA/RIMA, fato este que provocou o embargo da referida obra. Pelo demonstrado na Figura 02, o processo de execução da obra do empreendimento rodoviário iniciou em maio de 2012, e seu embargo ocorreu em abril de 2014, em virtude justamente da ausência dos estudos ambientais. Após quase um ano, as obras foram retomadas. Entretanto, a trajetória de sua implantação apresentou inúmeras dificuldades e obstáculos, tendo sido finalizado em 2019.

Como o EIA/RIMA não havia sido elaborado o processo de construção do rodoanel apresentou diversos entraves para a sua execução. Em meados de 2012, o Ministério Público Estadual (MPE) instaurou uma ação referente à manifestação do Instituto do Patrimônio Histórico e Artístico Nacional (IPHAN) sobre o empreendimento do rodoanel. A participação da instituição estava sendo exigida, tendo em vista que a área de implantação da rodovia fica próxima a Fazenda São Joaquim, edificada no ano de 1869 e que guarda um valor inestimável sobre a história de colonização do Piauí.

A Fazenda São Joaquim (Figura 03) está localizada a 24,9 km da cidade de Teresina entre as comunidades Atalaia e Santa Isabel e teria sua estrutura afetada com a instalação da obra, pois o traçado inicial do rodoanel iria alterar significativamente a geografia local, comprometendo a integridade física e ambiental da casa (IPHAN, 2013). Atentando-se para a análise das imagens de satélite do local da intervenção da rodovia nas proximidades da fazenda o traçado idealizado inicialmente percorreria a estrada "de piçarra" já estabelecida, como é possível perceber na imagem do ano de 2012.

R. gest. sust. ambient., Florianópolis, v. 10, n. 2, p. 45-64, jun. 2021. 
Figura 03 - Mudança do Traçado do Rodoanel próximo a Fazenda São Joaquim

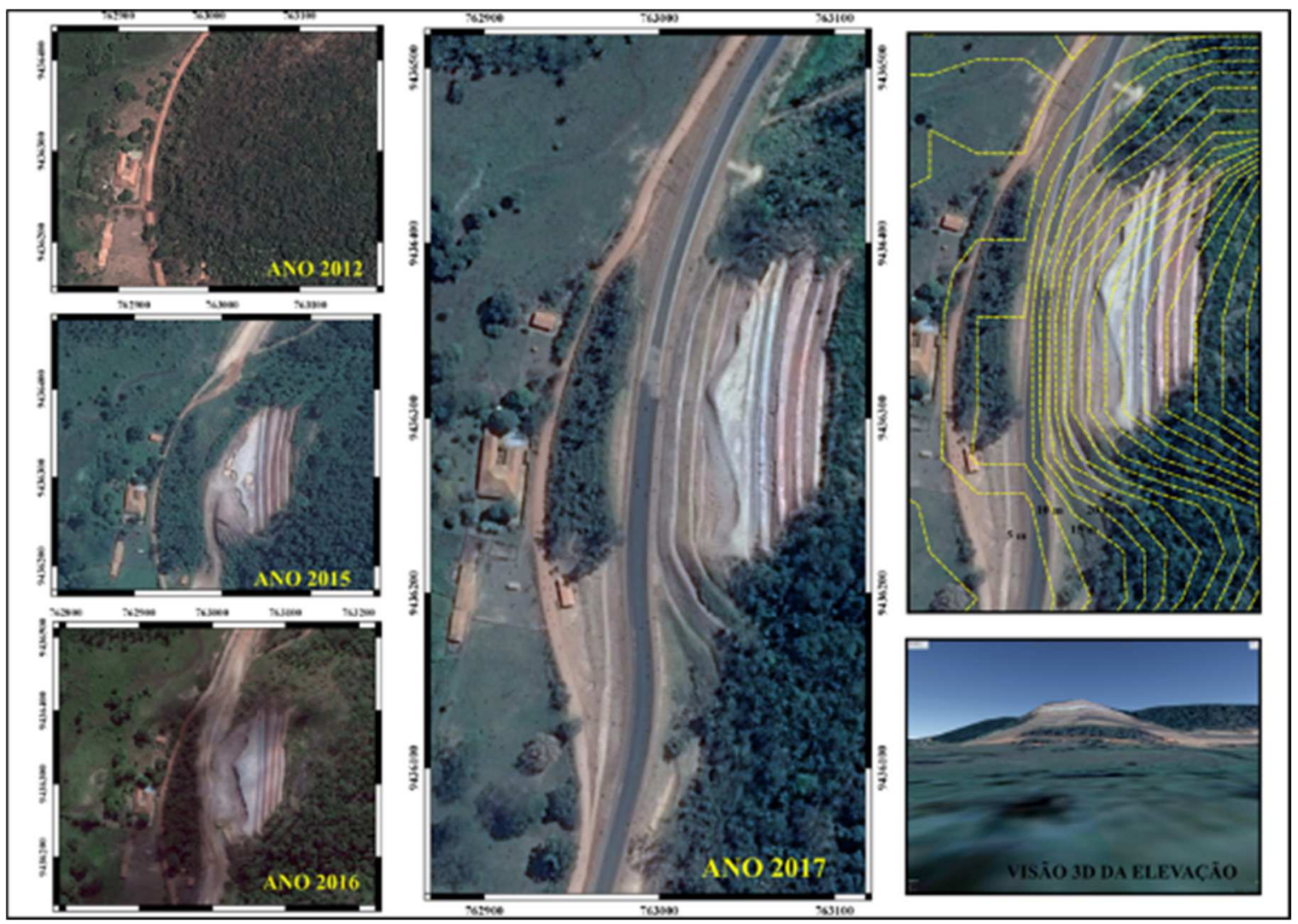

Fonte: Google Earth. Elaborado por MELO FILHO, 2019.

Os impactos gerados pelo empreendimento afetariam a fazenda, tanto em sua fase de instalação, quanto de operação, pois a intensidade das vibrações e ruídos provenientes do maquinário da obra acarretaria rachaduras na estrutura de sustentação da casa. Além do recorte no relevo, traria enorme perigo de deslizamento e soterramento da fazenda. É justamente por esses fatos que a elaboração de um EIA/RIMA é imprescindível para uma obra do porte do rodoanel de Teresina.

Bandeira e Floriano (2004) também enfatiza que os estudos sobre o meio antrópico devem envolver levantamento do patrimônio cultural, histórico e artístico na área onde a rodovia será instalada. Contudo, para a obra do rodoanel essa especificação não obteve sua devida atenção e somente após o proprietário da fazenda mover uma ação no ministério público a situação foi considerada.

Assim, a decisão tomada em audiência pública no MPE estabeleceu a elaboração de um Diagnóstico Não-Invasivo para a Fazenda São Joaquim. Assim, a pedido da SEMAR, a empresa de consultoria ambiental elaborou um Relatório de Diagnóstico Arqueológico Não Interventivo Invasivo para a Fazenda São Joaquim. Neste documento a empresa realizou a caracterização do local e avaliou os impactos R. gest. sust. ambient., Florianópolis, v. 10, n. 2, p. 45-64, jun. 2021. 
e as medidas de mitigação. Contudo, foi necessário realizar outro estudo, pois o IPHAN reprovou o primeiro relatório elaborado, sob a justificativa de inexpressividade nos dados apresentados (IPHAN, 2013).

Por fim, ficou afirmado que haveria uma mudança no traçado do rodoanel distanciando-o da área de abrangência da fazenda. Com a finalização da obra o local deveria transforma-se num espaço de visitação. Pelo exposto, os critérios e objetivos estabelecidos pelas determinações da legislação ambiental brasileira, em muitos casos, são interpretados e executados, sem, contudo, estarem em conformidade com a realidade do local (ARAÚJO, 2002).

Oliveira e Medeiros (2007), esclarecem que toda a análise para avaliar a influência dos impactos ambientais deve passar por etapas, com incursões a campo; busca de informações sobre a temática socioambiental condizente ao empreendimento a ser instalado, fazendo a fusão com análises cartográficas, físicoquímicas e espaciais. Desse modo, o objetivo é sempre alcançar a elaboração de estudos ambientais que traduzam a realidade na qual está inserida o empreendimento.

O empreendimento iniciou sua construção sem os estudos ambientais exigidos por lei. Os PCA's realizados para a obra não tiveram a supervisão do IBAMA e não foi apresentado EIA/RIMA como previsto na legislação. Dessa forma, a obra do rodoanel foi embargada, em abril de 2014, pelo MPE. Além dos problemas elencados, o MPE apresentou outra irregularidade em relação ao empreendimento rodoviário, à usurpação de áreas da União. Assim, a obra permaneceu suspensa até que houvesse a conclusão da ação ou fossem regularizadas as questões especificadas na liminar.

\section{AS ALTERAÇÕES AMBIENTAIS PROVOCADAS COM A INSTALAÇÃO DA RODOVIA}

A área de construção do rodoanel possui três assentamentos do INCRA, são eles: Assentamento Santana/ Nossa Esperança; Vale da Vitória e o Vale da Esperança, com um total de 278 famílias assentadas. A invasão de terras ocorreu em todos os assentamentos com prejuízo de área produtiva e retirada de areia das caixas de empréstimos, além de assoreamento do riacho Olho d’Água.

R. gest. sust. ambient., Florianópolis, v. 10, n. 2, p. 45-64, jun. 2021. 
As alterações ambientais, em virtude da execução da obra afetaram o meio ambiente físico, tanto no PCA de pavimentação asfáltica, quanto àquele referente à construção da ponte sobre o rio Poti. Neste caso, na obra viária em questão as alterações mais significativas ocorreram na fase de construção do empreendimento, com predomínio para os impactos no relevo; na estabilidade das encostas; na instauração de processos erosivos e também o assoreamento do rio Poti e do riacho Olho d’Água.

Conforme afirmam Bandeira e Floriano (2004, p. 07), deve haver sempre a identificação, descrição e localização dos pontos de sensibilidade ambiental ao longo do trecho de instalação da obra. Acrescentam, ainda, a importância da "[...] avaliação dos terrenos atingidos diretamente pelas obras, caracterizando a instabilidade dos maciços e taludes [...]". Por meio da verificação em campo, foi possível perceber que os recortes dos taludes em alguns pontos ao longo do trecho da rodovia já apresentam indícios de processos erosivos, embora tenha sido adotada pelo consórcio construtor da obra a técnica de hidrossemeadura para exercer proteção fundamental ao talude. O mosaico apresentado na figura 04 ilustra o surgimento desses processos.

Por meio da observação da figura 04 , evidencia-se que alguns trechos do rodoanel estão suscetíveis à ocorrência de deslizamento, necessitando de readequação a partir de novas obras no local. Essas falhas muitas vezes ocorrem, devido à realização deficiente do sulcamento e coveamento procedimentos que impedem a retenção do material ou da escolha errada das espécies.

R. gest. sust. ambient., Florianópolis, v. 10, n. 2, p. 45-64, jun. 2021. 
Figura 04 - Mosaico dos taludes de alguns trechos do rodoanel

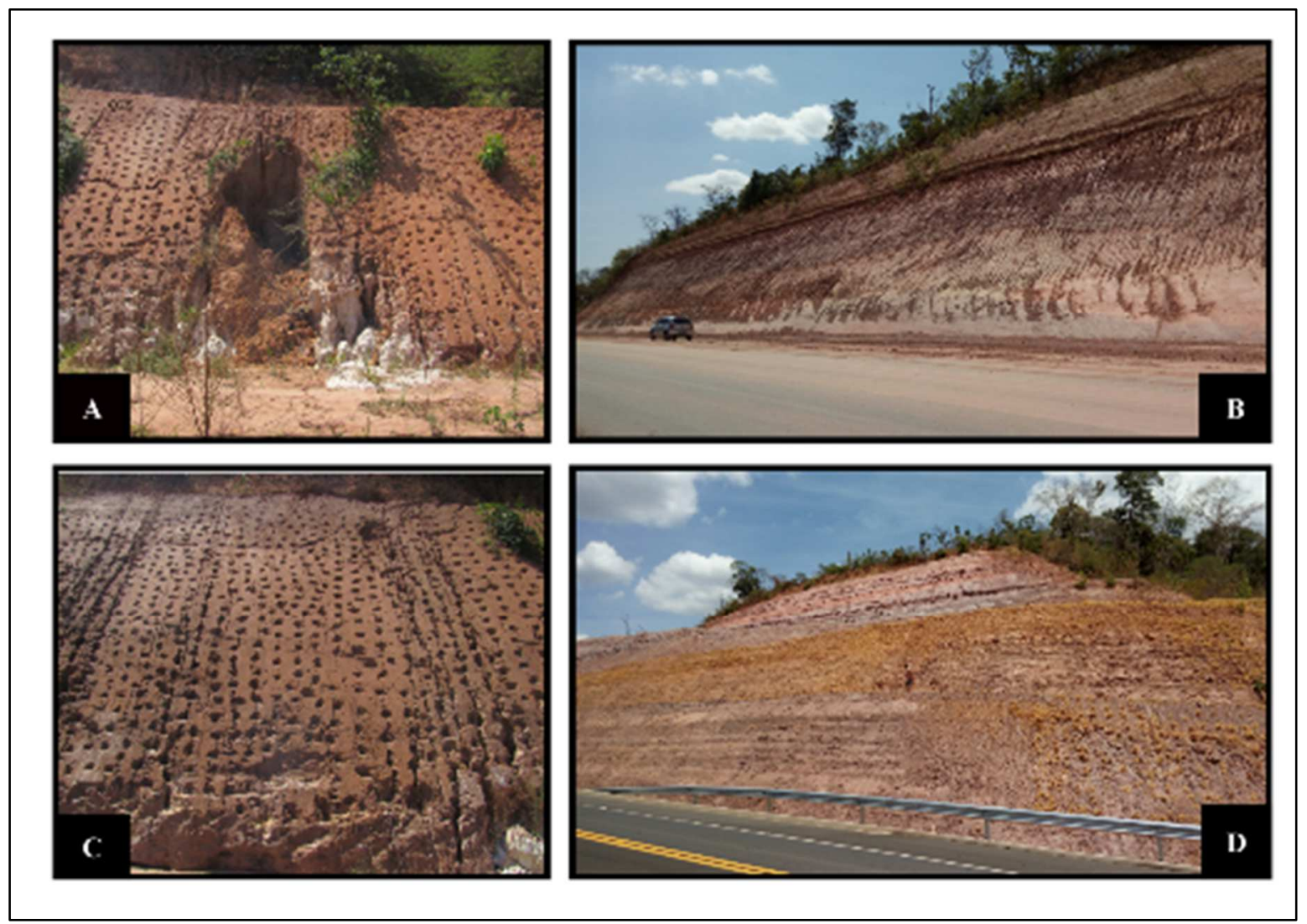

Fonte: Elaborado por MELO FILHO, 2018.

Em relação à instalação do traçado da rodovia por dentro das terras dos assentamentos um dos primeiros problemas evidenciados foi à perda de área produtiva, devido ao aumento da faixa de domínio ${ }^{4}$, reduzindo assim a área destinada à atividade da agricultura dos assentados. Além das perdas dos locais de plantio o desmatamento na faixa de domínio gerou, ainda, redução da cobertura vegetal e mudança na paisagem.

Analisando o processo de licenciamento realizado pela SEMAR, bem como o relatório organizado pelo INCRA, consta-se que não houve qualquer autorização para a realização deste desmatamento.

O Departamento Nacional das Estradas de Rodagem - DNER (2001) enfatiza que os impactos gerados por obras rodoviárias dependem também da largura e o uso das faixas de domínio, geometria e traçado da via e da comunicação do mesmo com o sistema viário.

\footnotetext{
${ }^{4}$ Segundo o DNIT, faixa de domínio corresponde a base física sobre a qual assenta uma rodovia, constituída pelas pistas de rolamento, canteiros, obras de arte, acostamentos sinalização e faixa lateral de segurança, até o alinhamento das cercas que separam a estrada dos imóveis marginais ou faixa de recuo.
}

R. gest. sust. ambient., Florianópolis, v. 10, n. 2, p. 45-64, jun. 2021. 
Conforme Simonetti (2010, p.20), existem parâmetros básicos para serem analisados na fase de estudo do traçado de uma rodovia, tais como: "[...] a geologia; relevo e topografia; as caraterísticas dos solos; pluviosidade e cobertura vegetal". A escolha do local para a instalação de um empreendimento rodoviário constitui a decisão mais crítica, pois a sua construção irá determinar a intensidade das alterações ambientais e sociais.

O estudo realizado para a implantação e pavimentação do rodoanel de Teresina apresentou a avaliação de vários aspectos supracitados acima, com exceção daqueles relacionados às alterações nos projetos de assentamento, pois em nenhum dos estudos ambientais realizados constava avaliações a esse respeito. $\mathrm{Na}$ elaboração dos referidos estudos deve haver as alternativas de localização do empreendimento, mapeamento de áreas legalmente protegidas, ou aquelas com restrições legais e/ou ambientais (COSTA, 2010). Além do conhecimento sobre "[...] as características do uso e ocupação do solo da região e da população residente/usuária do entorno da via em questão" (MUZZOLON JÚNIOR, 2010, p.06).

Contudo, essas recomendações não tiveram a devida atenção para execução do diagnóstico realizado para a obra do rodoanel de Teresina, pois tais informações obtidas com o referido estudo poderiam evitar danos, como por exemplo, nas áreas de preservação permanente, como é o caso dos locais de cultivo e cursos d'água dos assentamentos.

As áreas de preservação ambiental permanente são asseguradas por lei e devem ser preservadas. A figura 05 mostra a situação da área dos olhos d'água. De acordo, com o Código Florestal vigente a área de preservação permanente de riachos corresponde a 30 metros (artigo $4^{\circ}$ da Lei no 12.651, de 25.05.2012). Enquanto as áreas de preservação permanente no entorno de nascentes e olhos d'água são de 50 $\mathrm{m}$ de raio (artigo 4ํㅜㅇ Inciso IV, da lei $\mathrm{n}^{\circ}$ 12.727, de 17.10.2012). Mas os danos causados na área em análise, segundo o relatório do INCRA, correspondeu a 300 metros, em desacordo com a legislação.

R. gest. sust. ambient., Florianópolis, v. 10, n. 2, p. 45-64, jun. 2021. 
Figura 5 - Situação dos olhos d'água

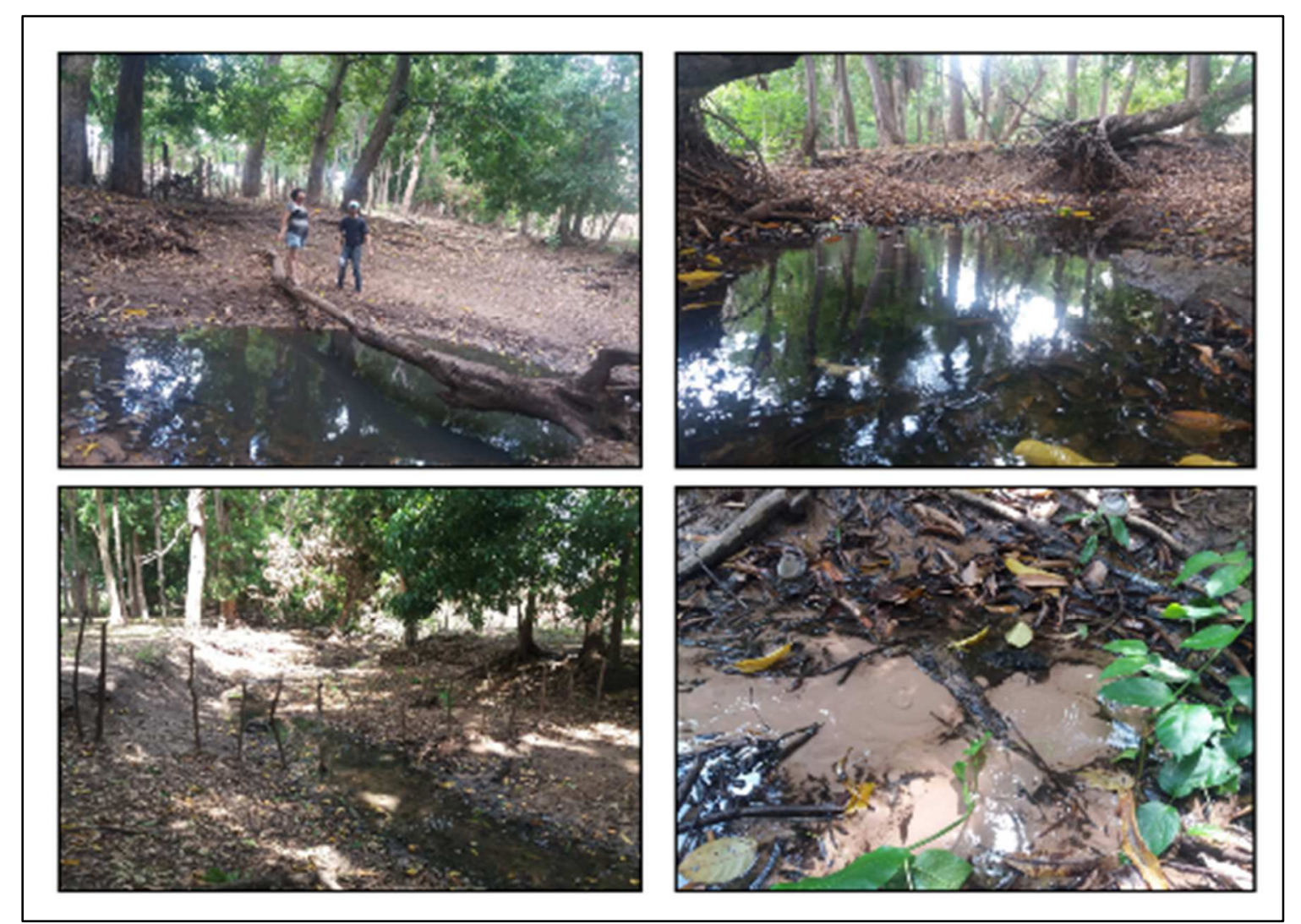

Fonte: Elaborado por MELO FILHO, 2018.

Além dos danos causados ao mananciais outro problema recorrente na fase de implantação de um empreendimento rodoviário está relacionado ao processo de terraplanagem. Para a construção do rodoanel de Teresina foram retiradas caixas de empréstimos das terras pertencentes aos assentamentos, sendo que a escavação foi precedida pelas operações de desmatamento, destocamento e limpeza. Essa atividade foi realizada "[...] sem licenciamento ambiental, e causou degradação visual da paisagem" (INCRA, 2015, p. 39).

Foram retiradas 09 caixas de empréstimos do assentamento Nossa Vitória e uma área de jazida, totalizando uma área total de 2,63ha de material retirado e utilizado no aterro da plataforma da rodovia. No Assentamento Santana/Nossa Esperança foram 11 caixas, totalizando uma área total de 2,61 ha. As alterações sofridas no assentamento Vale da Esperança consistiu no aprofundamento do açude, mas no relatório do INCRA não há informações a respeito dos danos em relação à retirada de material neste assentamento, tampouco do aprofundamento do açude. $A$

R. gest. sust. ambient., Florianópolis, v. 10, n. 2, p. 45-64, jun. 2021. 
justificativa apresentada no estudo se deve ao fato de que nos assentamentos Nossa Vitória e Santana/ Nossa Esperança os danos foram mais graves (INCRA, 2015).

As medidas de mitigação propostas pelo estudo ambiental feito pelo INCRA determinada o estabelecido nos assentamentos Nossa Vitória e Santana/Nossa Esperança nos locais das caixas de empréstimos a utilização desses espaços para a exploração da piscicultura, levando em consideração os aspectos do tipo de solo, inclinação de taludes, piso, impermeabilização, tamanho, profundidade e qualidade d'água. No entanto, essas medidas não foram executadas.

No que diz respeito aos danos causados aos mananciais de água, as ações deveriam consistir em limpeza manual dos olhos d'água e do leito do riacho para retirada do material oriundo do bota fora e do expurgo, bem como o reflorestamento de suas áreas de preservação permanente, garantido assim o escoamento adequado do riacho (INCRA, 2015). No entanto, essas medidas não foram executadas.

As medidas mitigadoras do processo de terraplanagem, o PCA de implantação e pavimentação do rodoanel ressaltou que o acúmulo de rejeitos nos leitos das vias deveria obedecer às recomendações do Plano de Recuperação de Áreas Degradadas - PRAD, sem maiores informações (SEMAR, 2014). Contudo, as determinações descritas no PRAD sugerem a fiscalização e acompanhamento das atividades previstas de recuperação, mas as visitas a campo e o registro fotográfico comprovam que as medidas ainda não foram atendidas, tampouco foi realizado um acompanhamento assíduo da evolução das determinações.

Pelas evidências demonstradas com a realização desta pesquisa, assegura-se a importância do controle, acompanhamento e supervisão no processo de instalação de uma obra rodoviária do porte do rodoanel de Teresina, pois as atividades de prevenção conseguem alcançar êxito em sua execução quando o processo prévio de elaboração do projeto consegue formular as ações de modo coerente com a realidade do ambiente a receber a instalação da obra viária.

\section{CONCLUSÃO}

Tomando como parâmetro a realização do empreendimento rodoviário, percebeu-se a falta de cuidado no cumprimento das regulamentações legais e deficiências nos estudos de avaliação efetivados conduzindo, dessa maneira, para situações de conflitos e desequilíbrio ambiental.

R. gest. sust. ambient., Florianópolis, v. 10, n. 2, p. 45-64, jun. 2021. 
Muito embora, os instrumentos (planos, normatizações e a legislação) apresentem um conteúdo preciso, direcionando os encaminhamentos necessários, ainda persiste a falta de participação daqueles indivíduos que são diretamente afetados e, por consequência, os que mais necessitam das ações planejadas. Constata-se também, lentidão em sua execução e reduzida atenção para as questões de monitoramento e fiscalização.

Sobre a implantação do rodoanel e os estudos ambientais realizados para a obra, observou-se que embora tenham sido executados o processo de avaliação apresentou fragilidades, pois nos PCA's elaborados os aspectos inerentes ao meio antrópico não foram analisados da maneira como determina as resoluções ambientais. Em razão disso, reforça-se a pertinência da preparação do EIA/RIMA.

A análise permite também salientar que as alterações geradas com a construção da obra acarretou em prejuízos ao meio ambiente, sobretudo, no que diz respeito a desmatamento de extensas áreas verdes. $O$ empreendimento provocou também alterações nos mananciais de água como o rio Poti e o riacho Olho d'Água. Evidenciou-se também a falta de licenciamento ambiental na execução de algumas atividades da obra rodoviária.

\section{REFERENCIAS}

ARAÚJO, Suely Mara Vaz Guimarães de. Licenciamento Ambiental e Legislação. Biblioteca Digital da Câmera dos Deputados. 2002. Disponível em: $<$ http://bd.camara.gov.br/bd/handle/bdcamara/1029 >. Acesso em: 18 ago. 2019.

BANDEIRA, Clarice; FLORIANO, Eduardo Pagel. Avaliação de impacto ambiental de rodovias. Caderno Didático, n. 8, Santa Rosa: ANORGS, 2004. Disponível em: < https://rodoviasverdes.ufsc.br/files/2010/03/Avalia\%C3\%A7\%C3\%A3o-de-impactoambiental-de-rodovias.pdf>. Acesso em: 18 ago. 2019.

BRASIL. Casa Civil da Presidência da República. Lei n. 6.938, de 31 de agosto de 1981. Dispõe sobre a Política Nacional do Meio Ambiente, seus fins e mecanismos de formulação e aplicação, e dá outras providências.

- Conselho Nacional do Meio Ambiente. Ministério do Meio Ambiente Resolução n. 001/86, de 23 de janeiro de 1986. Dispõe sobre critérios básicos e diretrizes gerais para a avaliação de impacto ambiental.

Conselho Nacional do Meio Ambiente. Ministério do Meio Ambiente. Resolução n. 237/97, de 19 de dezembro de 1997. Dispõe sobre a revisão complementação dos procedimentos e critérios utilizados para o licenciamento ambiental.

R. gest. sust. ambient., Florianópolis, v. 10, n. 2, p. 45-64, jun. 2021. 
CASTRO NETO, A. C. D. ; BATISTA, M. V. A. ; ABREU, I. G. . Transformações sócioespaciais na zona rural do município teresinense a partir das proximidades com a cidade de Teresina. In: Anais v simpósio internacional, VI simpósio nacional de geografia agrária. Questões agrárias na Panamazônia do século XXI: usos e abusos do território. 2011,. Belém: UFBA, 2011. v. 1. Disponível em: https://www.uespi.br/prop/siteantigo/XSIMPOSIO/TRABALHOS/INICIACAO/Ciencias $\% 20$ Humanas $\% 20$ e\%20Letras/TRANSFORMACAES\%20SOCIO-

ESPECIAIS\%20NA\%20ZONA\%20RURAL\%20DO\%20MUNICIPIO\%20TERESINEN SE\%20A\%20PARTIR\%20DAS\%20PROXIMIDADES\%20COM\%20A\%20CIDADE\%2 ODE\%20TERESINA.pdf. Acesso em: 28 set. 2019.

COSTA, Maria Roberto; SÁNCHEZ, Luis Henrique. Avaliação do desempenho ambiental de obras de recuperação de rodovias. Revista Escola de Minas. v. 63. p. 247-254. 2010.

Disponível

em:< https://www.scielo.br/pdf/rem/v63n2/remv63n2a07.pdf> . Acesso em: 28 out. 2019.

COSTA, Roberta Maria. O papel da supervisão ambiental e proposta de avaliação de desempenho ambiental em obras rodoviárias. São Paulo, 2010. Dissertação (Mestrado - em Engenharia) - Escola Politécnica da Universidade de São Paulo, 351 p. Disponível: < https://teses.usp.br/teses/disponiveis/3/3134/tde-08022010104633/publico/Dissertacao Roberta Maria Costa.pdf>. Acesso em: 15 jul. 2019.

CRUZ, Franciane Cougo da; CRUZ, Anderson Cougo da; ROSSATO, Marivane Vestena. Identificação e Avaliação de Impactos Ambientais: um estudo de caso. Revista Eletrônica em Gestão, Educação e Tecnologia Ambiental. v.18. no 02. p. 777 - $791.2014 . \quad$ Disponível em: < https://periodicos.ufsm.br/reget/article/viewFile/13549/pdf >. Acesso em: 28 set. 2019.

ESPINDOLA, Giovana Mira; DA COSTA CARNEIRO, Eduilson Lívio Neves; FAÇANHA, Antonio Cardoso. Four decades of urban sprawl and population growth in Teresina, Brazil. Applied geography, v. 79, p. 73-83, 2017.

DNER. Departamento Nacional de Estradas de Rodagem. Diretoria de Engenharia Rodoviária. Divisão de Estudos e Projetos. Serviço de Estudos Rodoviários e Ambientais. Manual Rodoviário de Conservação, Monitoramento e Controle Ambientais. Rio de Janeiro, 2001.

IBGE. Instituto Brasileiro de Geografia e Estatística, 2010. Censo 2010.

INCRA, Instituto Nacional de Colonização e Reforma Agrária. Relatório do Levantamento dos danos ambientais causados pelo rodoanel de Teresina nos projetos de assentamentos Nossa Vitória, Santana/Nossa Esperança e Vale da Esperança. Teresina. 2015. 79 p.

IPHAN, Instituto do Patrimônio Histórico e Artístico Nacional. Relatório de Diagnóstico Arqueológico Não Interventivo Invasivo para a Fazenda São Joaquim. 2013.

R. gest. sust. ambient., Florianópolis, v. 10, n. 2, p. 45-64, jun. 2021. 
LEITE, Thiago Almeida; SOBRAL, Ivana Silva; BARRETO, Fernanda Karla Barbosa. Avaliação dos impactos ambientais e sociais como subsidio para o licenciamento ambiental do projeto de assentamento de reforma agrária Maria Bonita I Poço Redondo/SE. Boletim Goiano de Geografia. v. 31. nº 02. p. 69-81. 2011.

LIMA, Silvia Maria Santana Andrade; LOPES, Wilza Gomes Reis; FAÇANHA, Antonio Cardoso. A relação entre as áreas urbana e rural em cidades contemporâneas: Estudo em Teresina, Piauí, Brasil. Revista Spacios, v. 38, p. 32-47, 2017.

MORAES, Luis Carlos. Licenciamento Ambiental: do programático ao pragmático.

Sociedade \& Natureza. v. 35. no 02. p. $215-226.2016$.

MUZZOLON JÚNIOR, Renato. Controle Ambiental em Rodovias. Revista Técnico Cientifica do CREA-PR. 2 ${ }^{a}$ ed. p. 1-17. 2014.

OLIVEIRA, Frederico Fonseca Galvão; MEDEIROS, Wendson Dantas de Araújo. Bases teórico-conceituais de métodos para a avaliação de impactos ambientais em EIA/RIMA. Mercator. v. 6. no 11. p. 79 -92. 2007.

SEMAR, Secretaria de Meio Ambiente e Recursos Hídricos do Piauí. Programa de Controle Ambiental para a implantação e pavimentação asfáltica do rodoanel de Teresina. 2014.

SILVA, Edna Lúcia da; MENEZES, Estera Muszkat. Metodologia da pesquisa e elaboração de dissertação. 4 ed. rev. atual. Florianópolis, UFSC. 2005.

SILVA, Silvana de Sousa; FAÇANHA, Antonio Cardoso. (Re) Produção espacial e área central de Teresina (PI): Preposições da Agenda 2015. Caminhos da Geografia. v. 17, n. 58. 2016. p. 01-15.

SIMONETTI, H. Estudo de Impactos Ambientais Gerados pelas Rodovias: sistematização do processo de elaboração de EIA/RIMA. 2010. 55 f. Trabalho de Diplomação (Graduação em Engenharia Civil) - Departamento de Engenharia Civil, Universidade Federal do Rio Grande do Sul, Porto Alegre.

TERCEIRO, Amélya Djiullya Silva; ESPINDOLA, Giovana; CARNEIRO, Eduilson L.N.C. Paisagem urbana em Teresina: Implicações da distribuição espacial da densidade populacional. Gaia Scientia, v. 12, n. 1, 2018.

R. gest. sust. ambient., Florianópolis, v. 10, n. 2, p. 45-64, jun. 2021. 